\title{
Efficacy of Risedronate and Vitamin D3 Once-weekly on Bone Mineral Density in Women Patients with Osteoporosis
}

\author{
Daniel Lopez-Hernandez ${ }^{1,2, ~ *, ~ N a d h y i e l i ~ O r o z c o-C a m p o s ~}{ }^{1}$, Leticia Brito-Aranda ${ }^{2}$, \\ Maria de la Luz Lopez-Hernandez ${ }^{2}$, Aurora Bautista-Marquez ${ }^{1}$, Vesta Richardson ${ }^{1}$ \\ ${ }^{1}$ Sub-Directorate of Prevention and Health Protection, Institute of Security and Social Services of State Workers, Mexico City, Mexico \\ ${ }^{2}$ Department of Biostatistics and Epidemiology, Center for Research and Continuing Education (CENINVEC), Nezahualcoyotl City, Mexico
}

Email address:

daniel16042016@gmail.com (D. Lopez-Hernandez),nadhyieli.orozco@issste.gob.mx (N. Orozco-Campos), letty.brito@gmail.com (L. Brito-Aranda), luz.lopez.hernandez@gmail.com (M. de la L. Lopez-Hernandez), aurora.bautista.marquez@gmail.com(A. Bautista-Marquez), vesta.richardson@gmail.com (V. Richardson)

${ }^{*}$ Corresponding author

\section{To cite this article:}

Daniel Lopez-Hernandez, Nadhyieli Orozco-Campos, Leticia Brito-Aranda, Maria de la Luz Lopez-Hernandez, Aurora Bautista-Marquez, Vesta Richardson. Efficacy of Risedronate and Vitamin D3 Once-weekly on Bone Mineral Density in Women Patients with Osteoporosis. Clinical Medicine Research. Special Issue: Globalization and Advances on Non-Communicable Chronic Diseases.

Vol. 8, No. 5, 2019, pp. 93-100. doi: 10.11648/j.cmr.20190805.11

Received: August 10,2019; Accepted: September 10, 2019; Published: September 30, 2019

\begin{abstract}
There has been a limited evaluation of the efficacy of administered vitamin-D3 and bisphosphonate in a single pill (once-weekly) on changes of Bone Mineral Density (BMD), speciality in elderly people. To evaluate the changes in BMD, using Risedronate and vitamin D3, in patients from the first level of primary care after a period of more than 2 years of followup. An observational and retrospective cohort study, in a non-controlled, real-life setting nested to a database was designed. Records of participants between March-04-2008 and June-27-2012. Mexican patients from 21 Clinics of Family Medicine. The database is characterized by all patients received Risedronate $(35 \mathrm{mg}$ ) and vitamin-D3 (2800 IU) combined in a single pill, administered once-weekly. BMD was determined in the distal portion of the radius bone using an Omnisense-7000S bone densitometer. The Kaplan-Meier method was used to estimate cumulative probabilities. Hazard ratios (HRs) were estimated using Cox-proportional hazard-models. A total of 14,721 women were included. The mean time of treatment was 27.06 months (interquartile-range $=26.00-29.00)$; the crude $\mathrm{HR}$ in patients with osteoporosis was $2.483(95 \% \mathrm{CI} 1.806-3.414)$ times higher than their counterparts with osteopenia. In relation to age, the increase in BMD was $26 \%$ higher $(\mathrm{HR}=0.739$; $95 \% \mathrm{CI} 0.712$ 0.766) in patients with 60 or more age than their counterparts aged $\leq 59$ years. The duration of treatment with risedronate/vitamin D3 once-weekly depends on the target population and need strict monitoring of BMD particularly for those patients who have a treatment for more of 18 months due to the risk of decreased BMD.
\end{abstract}

Keywords: Risedronate (35 mg) and Vitamin D3 (2800 IU), Retrospective Cohort Study, Bone Mineral Density, Cox Proportional Hazard Models

\section{Introduction}

Osteoporosis is considered a public health problem worldwide (affecting approximately 200 million people according to the International Osteoporosis Foundation [1]) that predisposes affected individuals to fractures $[1,2]$. Osteoporotic fractures also represent an important public health problem due to the social and financial impacts that are generated. Annually, osteoporosis leads to more than 8.9 million fractures, of which over 4.5 million occur in Europe and North America [2]. Moreover, the prevalence of osteoporosis increases with age, affecting up to $80 \%$ of women over 80 years of age [3]. Several studies have shown that bisphosphonates are safe and effective for the treatment and prevention of postmenopausal osteoporosis and osteoporosis induced by glucocorticoid agents [4-18]. These 
drugs are the first-line agents for the medical treatment of osteoporosis around the world [19-21]. It is well established that Risedronate $(5 \mathrm{mg})$ compared to placebo reduces the risk of vertebral and non-vertebral bone fractures (by 33 to 65\%) $[6,7]$, and a dose of $5 \mathrm{mg}$ is recommended in postmenopausal women every 24 hours for 2 or 3 years. This reduces bone turnover [4-6] and increases bone mass in the lumbar spine, femoral neck, femoral trochanter, proximal femur, total hip and diaphysis of the radius $[6,9,10,12,13]$. On the other hand, the use of Risedronate at a dose of $35 \mathrm{mg}$ once-weekly provides the same efficacy and safety [13] and in combination with vitamin D3 (2800 UI), increases bone mineral density (BMD) in the diaphysis of the radius in postmenopausal women. The response is best observed in women with osteoporosis and obesity [22]. The aim of this study was to evaluate the changes in BMD, in the diaphysis of the radius, using Risedronate and vitamin D3 (35 mg/2800 IU) combined in a single pill (once-weekly), in patients (from the first level of primary care) with osteopenia and osteoporosis after a period of more than 2 years of follow-up.

\section{Material and Methods}

\subsection{Study Design, Patient Enrolment and Ethical Considerations}

We conducted an observational and retrospective cohort study in Mexican patients from ISSSTE (Instituto de Seguridad y Servicios Sociales de los Trabajadores del Estado) in a non-controlled, real life setting nested to a database. This database is characterized by having sociodemographic information of patients and records of BMD since baseline to several periods of time after the administration of risedronate and vitamin D3 (single pill) once-weekly. Diagnosis of osteoporosis and osteopenia was based on BMD measurements specified in the WHO Report, Brussels, Belgium, May 5-7, 2004 [2]. A total of 66,398 records of subjects (aged 21 to 106 years) were included. All patients were detected and monitored through outpatient family medicine consultations between March 04, 2008 and June 27, 2012 (women $=66,386 ; 99.98 \%, 95 \%$ confidence interval [CI] 100.0-100.0; and men $=12 ; 0.02 \% 95 \%$ CI 0.0 $0.0)$. Of this total population $(n=66,398), 12,901(19.4 \%$; 95\% CI 19.1-19.7), and 47,344 (71.3\%; 95\% CI 71.0-71.6) individuals were diagnosed with osteopenia and osteoporosis, respectively. After clinical diagnosis but lacking a subsequent measure of the BMD, a total of 40,780 patients were excluded. A total of 25,618 (aged 24 to 102 years) patients were analysed to determine the period of follow-up of treatment (women $=25,615 ; 99.99 \%, 95 \%$ CI $100.0-100.0$ versus men $=3 ; 0.01 \%, 95 \%$ CI $0.0-0.0)$. After analyses of the follow-up period, only 14,721 records had information about the duration of follow-up time. Therefore, we only analysed information from this group of participants. The study was conducted in accordance with Good Clinical Practices covered by Mexican law and the Declaration of Helsinki. Identification numbers were assigned to maintain the anonymity of the patients.

\subsection{Bone Mineral Density Measurements and Operational Definitions}

The WHO recognises bone densitometry as the reference method for the diagnosis of osteoporosis in postmenopausal women;[2] therefore, BMD was performed using the Omnisense 7000S device (Sunlight, Germany) according to the manufacturer's recommendations (Sunlight Medical, Ltd., Model: Sunlight Omnisense $\left.{ }^{\mathrm{TM}} 7000 \mathrm{~S}\right)$. A baseline BMD was determined in the distal portion of the radius bone using an Omnisense 7000S bone densitometer (precision: Intraobserver coefficient of variance $=0.2-0.3 \%$, and Interobserver coefficient of variance $=0.3-0.7 \%$; "in vivo"). Subsequently, 4 bone densitometries were measured after starting treatment. Osteopenia and Osteoporosis were defined according to the operational definition of the WHO as a Tscore value between -1.0 and -2.5 standard deviations (SD), and $\mathrm{T}$-score $<$ or $=-2.5 \mathrm{SD}$ of the maximum density average value for a young normal adult [2].

\subsection{Drug Information, Dosage and Administration}

All patients received Risedronate $(35 \mathrm{mg}$ ) and vitamin D3 (2800 IU) combined in a single pill and administered onceweekly. Although our analysis is retrospective, is important to clarify that during the treatment period, all patients were instructed to take the drug with at least $120 \mathrm{~mL}$ of water, on an empty stomach, at least 30 minutes before breakfast. Patients were also to remain upright (sitting or standing) for at least $1 \mathrm{~h}$, according to the recommendations of the data sheet.

\subsection{Study Variables and Statistical Analysis}

Sociodemographic variables included in the present study were sex, age, T-score, time of treatment, and family and personal medical history of non-communicable diseases. For Cox regression analysis, the primary outcome variable was the duration of treatment associated with the increase of $\mathrm{BMD}$, which was measured as the difference between the date of definitive suspension of the prescribed drug and the start date of drug administration. Therefore, the outcome of the study was the increase of BMD, measured as the difference between the values of the third T-score minus the baseline $\mathrm{T}$-score value (improvement). The dependent variable was the improvement of BMD. Continuous variables are expressed as the mean and standard deviation (SD). Comparisons between the first and third values of densitometry were performed using the Wilcoxon signedrank test. Categorical variables are described by absolute frequency and the corresponding 95\% confidence interval and were compared using the Yates's corrected chi-square test. The Kaplan-Meier method was used to estimate cumulative probability regarding increase of the BMD of the patients. Hazard ratios (HRs) were estimated using Cox proportional hazard models and their 95\% CIs were calculated using a logarithmic transformation method. We 
use the Cox regression procedure for modelling the time to increase the BMD as a specified event, based on the values of baseline $\mathrm{T}$-scores as time-dependent covariates. We considered a $\mathrm{p}$ value $<0.05$ to be statistically significant.

\section{Results}

\subsection{General Characteristics of the Study Population at Baseline}

We included a total of 14,721 women with osteopenia $(\mathrm{n}=$ 75 ; $0.5 \%$, IC 95\% 0.4-0.6) and osteoporosis $(n=14,646$; $99.5 \%$, IC 95\% 99.4-99.6). The mean age of the patients, was 64.78 years $(\mathrm{SD}=9.489$; Median $=64.00$; range 24 to 101 ;
Interquartile range $[\mathrm{IQR}]=58.00-71.00)$. The mean time of treatment was 27.06 months $(\mathrm{SD}=3.26$; median $=27.00$; range 0 to 33 months; IQR $=26.00-29.00)$. Of the total population, $68.6 \%(\mathrm{n}=10,102 ; 95 \%$ CI $67.8-69.3)$ were from the population patients with 60 or more age (Osteopenia $=42$; $0.4 \%, 95 \%$ CI $0.3-0.5$ versus Osteoporosis $=10,060 ; 99.6 \%$, 95\% CI 99.5-99.7), and 31.4\% were participants aged $\leq 59$ years $(n=4,619 ; 95 \%$ CI $30.7-32.2)$, of these patients, 33 were diagnosed with osteopenia $(0.7 \%$; $95 \%$ CI $0.5-1.0)$, and 4,586 with osteoporosis (99.3\%; 95\% CI 99.0-99.5) (Table 1). The average age in elderly persons was 64.51 years (median $=63$ years; interquartile range $[\mathrm{IQR}]=57-71$ years, range $=78$ ).

Table 1. Number of patients regarding to the time from administration of prescribed drug.

\begin{tabular}{|c|c|c|c|c|c|c|c|}
\hline & N (Baseline) & 6 months & 12 months & 18 months & 24 months & 30 months & 36 months \\
\hline Global & 14721 & 14710 & 14700 & 14584 & 13198 & 3424 & \\
\hline Osteopenia & 75 & 75 & 75 & 75 & 75 & 75 & 75 \\
\hline Subjects $\leq 59$ years old & 33 & 33 & 33 & 33 & 33 & 33 & 33 \\
\hline Subjects $\geq 60$ years old & 42 & 42 & 42 & 42 & 42 & 42 & 42 \\
\hline Osteoporosis & 14646 & 14635 & 14625 & 14509 & 13123 & 3349 & \\
\hline Subjects $\leq 59$ years old & 4586 & 4582 & 4578 & 4534 & 4099 & 594 & \\
\hline Subjects $\geq 60$ years old & 10060 & 10053 & 10047 & 9975 & 9024 & 2755 & \\
\hline
\end{tabular}

Source: Prepared by the authors using information from the database.

Clinical comorbidities and risk factors found in our patient group are as follows: hypertension $(\mathrm{n}=2,764 ; 18.8 \%$, IC $95 \%$ 18.2-19.5), diabetes $(n=1,369 ; 9.3 \%$, IC 95\% 8.8-9.7), cancer $(n=52 ; 0.4 \%$, IC 95\% 0.3-0.4), arthritis $(n=403$; $2.7 \%$, IC 95\% 2.5-3.0), alcohol consumption $(n=1,360$; $9.2 \%$, IC $95 \% 8.6-10.0)$, sedentary lifestyle $(n=4,834$; $32.8 \%$, IC 95\% 32.1-33.6), medical family history of osteoporosis $(n=1,049 ; 7.1 \%$, IC 95\% 6.7-7.6), and use of hormonal therapy $(\mathrm{n}=124 ; 0.8 \%$, IC 95\% 0.7-1.0).

\subsection{Changes of Bone Mass Density}

We observed a significant increase of BMD (Mean of the $\mathrm{T}$-score value (third densitometry) $=-2.51, \mathrm{SD}=0.83$ ) compared to the baseline values (Mean of baseline T-score $=$ $3.33, \mathrm{SD}=0.72$ ). The average difference between both values was 0.82 units (IC 95\% 0.80-0.83, p value $=<0.001$ ) (Figure 1) and those differences were more evident in patients with osteoporosis.

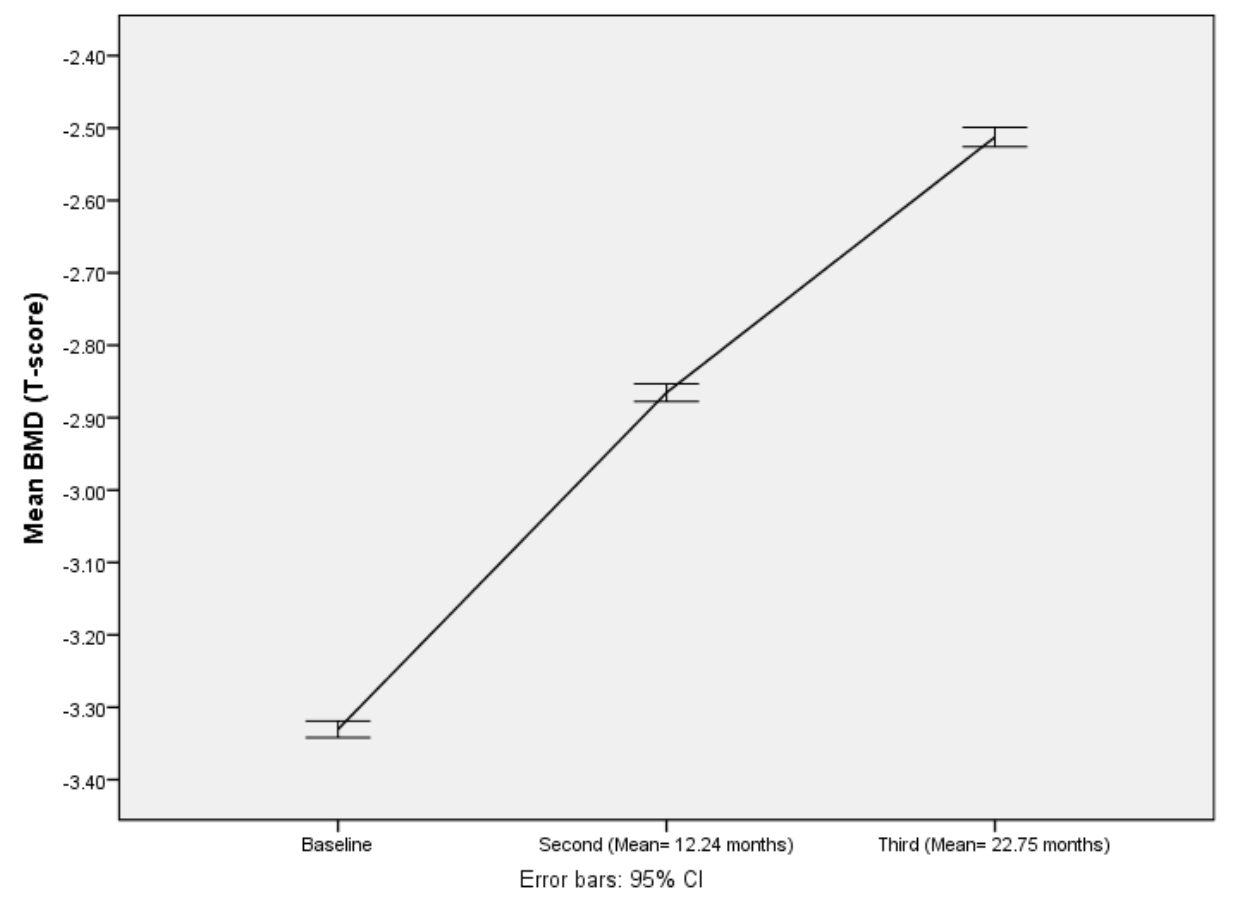




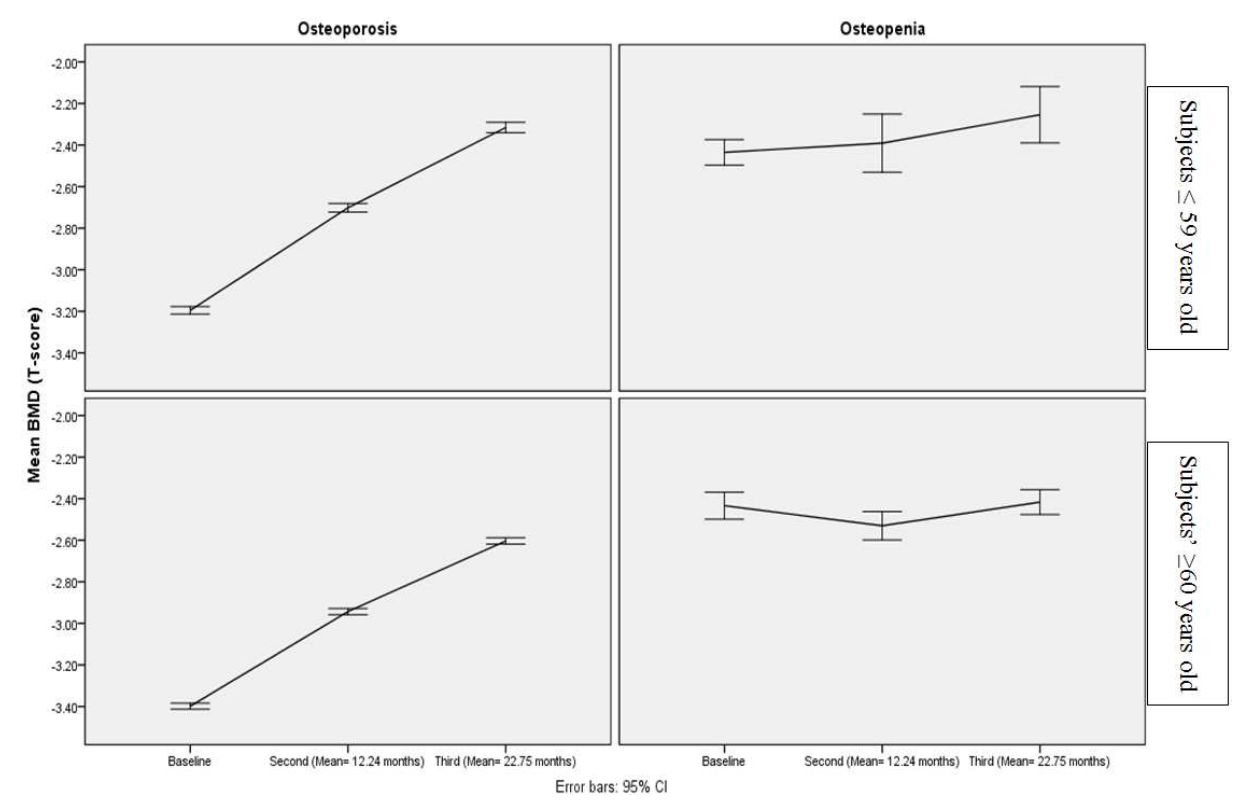

b)

Figure 1. Average values ( $n=14$ 721) of bone mineral density (BMD): a) Values of mean BMD according to time of densitometry study, b) Values of mean $B M D$ in relation to age and diagnosis.

Moreover, 13,926 patients $(94.6 \%, 95 \%$ CI $94.2-95.0)$ improved their BMD score and $795(5.4 \%, 95 \%$ CI 5.0-5.8) showed no improvement from their previous clinical condition (262 patients without change of their T-score values; $33.0 \%$, 95\% CI 29.6-36.4, and 533 patients with a decrease of their BMD; $67.0 \%, 95 \%$ CI $63.6-70.4)$.

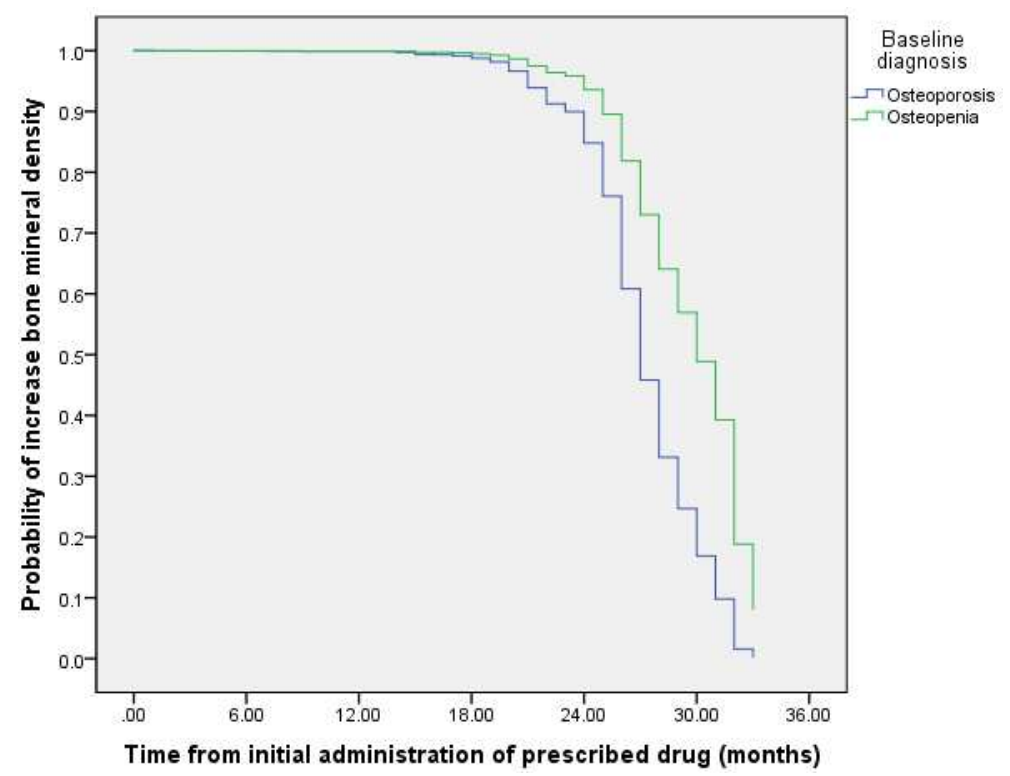

Figure 2. Analysis of Kaplan-Meier model in total population: Survival curve. probability regarding increase of the bone mineral density (BMD) of the patients. Outcome (improvement).

\subsection{Usefulness of Treatment}

Ninety-four percent of patients achieved some degree of improvement ( $\mathrm{n}=13,926 ; 95 \%$ CI 94.2-94.9), 3.62\% $(\mathrm{n}=533$; $95 \%$ CI $3.3-3.9)$ and $1.78 \%$ of patients $(n=262$; $95 \%$ CI $1.6-$ 2.0) showed a decrease of their BMD or no change of the Tscore value after treatment compared to the baseline T-score, respectively. Of the total of 13,926 patients with an improvement of their BMD, 7,697 (55.3\%; 95\% CI 54.4-
56.0) had no change in their initial diagnosis $(7,660$ remained with osteoporosis, and 37 with osteopenia). However, 6,229 patients $(44.7 \%, 95 \% \mathrm{CI} 44.0-45.6)$ had a change from their previous clinical condition (1 patient from osteopenia to normal T-score value [0.02\%; 95\% CI 0-1.3], 5,679 patients from osteoporosis to osteopenia [91.17\%; 95\% CI 90.5-91.8] and 549 patients from osteoporosis to normal T-score value, $8.81 \%$; 95\% CI 8.2-9.5). Moreover, as shown in figures 2 and 3 , we observed a different probability to increase the 
BMD between patients with osteopenia and osteoporosis. Pass 24 month, the patients with osteoporosis had a lower probability of improving their BMD compared with their counterparts with osteopenia ( $p$ value of long rank $=<0.001$ ), and a higher risk of decreasing their BMD with prolonged treatments (Figure 2).

Furthermore, patients with osteopenia and aged $\geq 60$ years have a greater probability of increasing their BMD and a lower risk of decreasing their BMD than patients with 59 years old or less (Figure 3 ). The probability of increasing the BMD in patients with osteoporosis was $2.483(95 \%$ CI 1.806-3.414) times higher than their counterparts with osteopenia. However, the probability to increase the BMD was higher in elderly patients than their counterparts aged $\leq$ 59 years $(\mathrm{HR}=3.426$; 95\% CI 2.157-5.440, $\mathrm{p}<0.001$ vs. $\mathrm{HR}=1.755 ; 95 \%$ CI $1.131-2.723, \mathrm{p}=0.012)$.

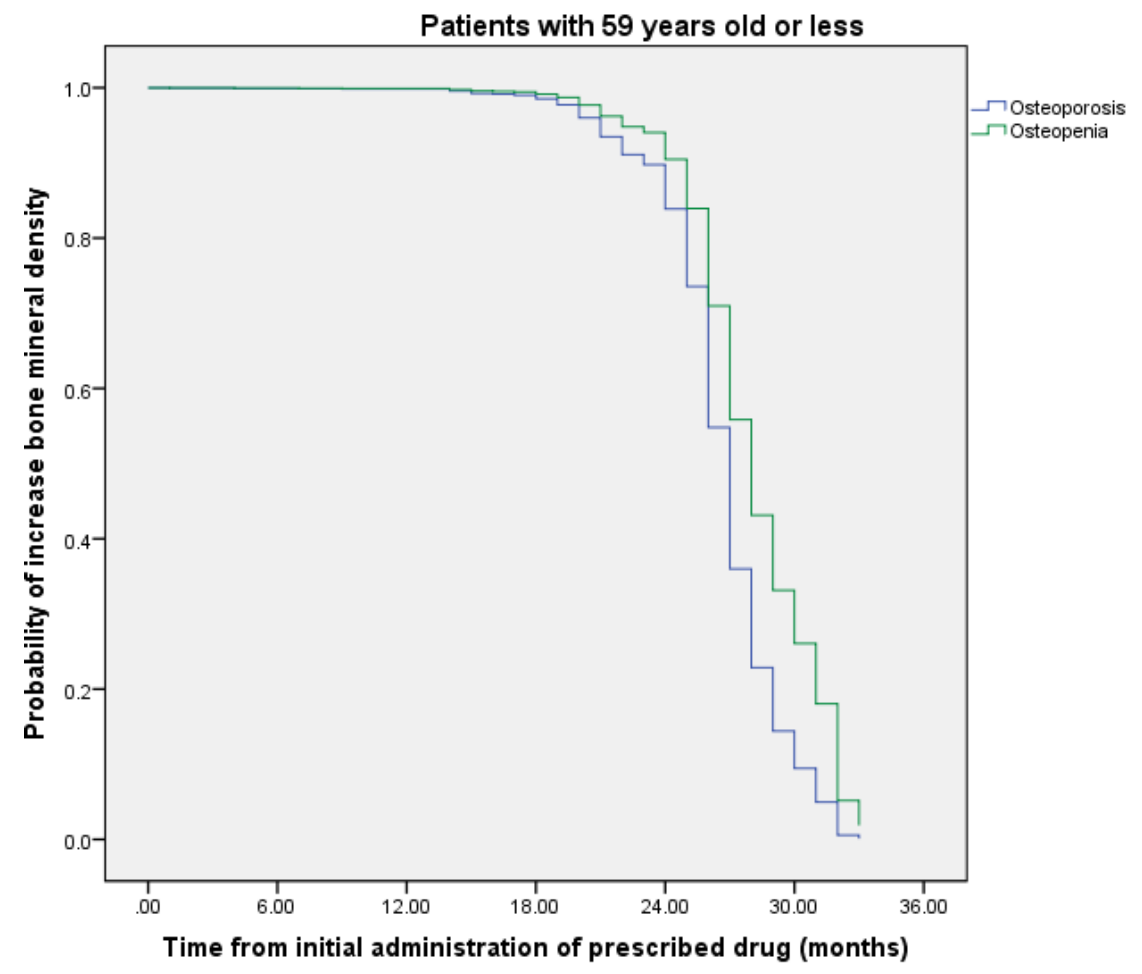

a)

Patients with 60 years old or more

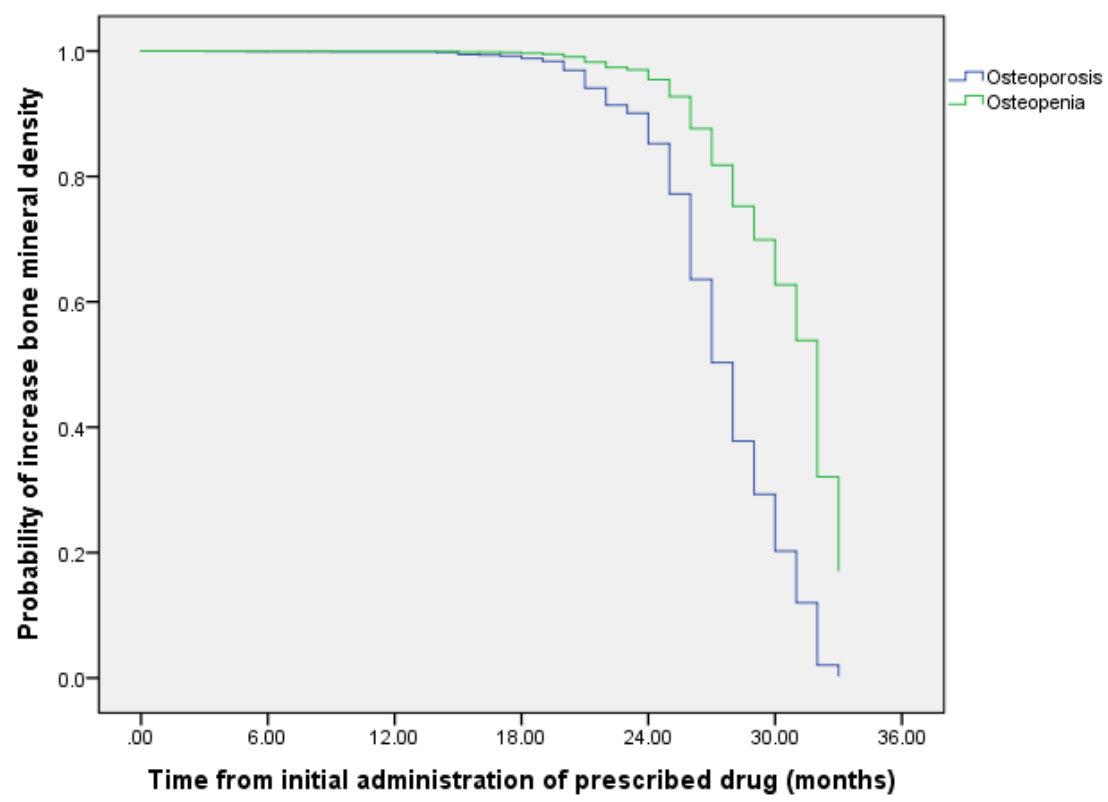

b)

Figure 3. Analysis of Kaplan-Meier model, in population, by age: Survival curve. a) probability of increases bone mineral density (BMD) of patients with aged $\leq 59$ years, b) probability of increases bone mineral density (BMD) of patients with aged $\geq 60$ years, respectively. Outcome (improvement). 


\section{Discussion}

\subsection{Effect of Risedronate and Vitamin D3 Once-weekly on Bone Mineral}

In the present study, we found a significant difference in baseline T-score values regarding the duration of treatment; on average, there was an increase of $23.66 \%$ in the BMD of the total study population (Median=18.92\%; IQR= 10-32.26). These findings are consistent with the results reported by Zoehrer et al [18]. They showed that after 3- and 5-years of treatment with risedronate $(5 \mathrm{mg} /$ day, orally) and $1000 \mathrm{mg}$ elemental calcium per day the degree of mineralization increased significantly in the risedronate as well as in the placebo group, compared with baseline [18]. However, this degree of mineralization did not exceed normal mineralization, suggesting that the changes at the material level of the bone matrix may contribute to risedronate antifracture efficacy in osteoporotic patients [18]. Similarly, in the United State population, an increase of BMD was observed [9]. This increase of the BMD at the hip trochanter, total hip, femoral neck, and lumbar spine was observed after 12 months of treatment with administration of risedronate $35 \mathrm{mg}$ onceweekly compared with baseline [9]. Moreover, in postmenopausal women from North and South America, and Europe the use of risedronate at $5 \mathrm{mg}$ and $35 \mathrm{mg}$ has a similar increase of BMD from baseline in the lumbar spine, total proximal femur, femoral neck and femoral trochanter [13]. Delmas et al showed that in postmenopausal women with osteoporosis who received $75 \mathrm{mg}$ of risedronate on 2 consecutive days each month or $5 \mathrm{mg}$ daily for 12 months, after 2 years there were similar increments of the BMD in the lumbar spine $(3.4 \%+/-0.16$ and $3.6 \%+/-0.15$; respectively) [23]. Similar results were obtained with the use of $75 \mathrm{mg}$ of risedronate once a month $(3.5 \%$; 95\% CI 3.15-3.93) after 1 year [24]. Moreover, in women and men with osteoporosis induced by corticosteroids the use of risedronate $5 \mathrm{mg}$ (once daily for 12 months) demonstrated an increase of BMD at the lumbar spine, femoral neck and femoral trochanter [12]. In addition, in men with osteoporosis from Eastern and Western Europe, Lebanon, Australia and the United States the use of risedronate $(35 \mathrm{mg}$ ) once-weekly increased the BMD (in 6\%) after 2 years of treatment [10]. This effect was observed at the lumbar spine, total proximal femur, femoral trochanter and femoral neck [10]. However, the increase of BMD appears to be dependent on the duration of treatment and dose. McClung et al reported that the use of risedronate at a dose of $150 \mathrm{mg}$ once a month provided similar efficacy and safety at 2 years compared with risedronate at $5 \mathrm{mg}$ daily, for the treatment of postmenopausal osteoporosis (4.2\%; CI 95\% 3.68 to 4.65) [25]. Another low-dose regimen was used in a Japanese population with similar results [14]. The use of risedronate once-weekly (with a dose of $17.5 \mathrm{mg}$ ) had equivalent efficacy to the use of once-daily treatment with $2.5 \mathrm{mg}$ risedronate with favourable safety profiles [14]. However, although $94.6 \%$ of our total study population had an increase of BMD compared with their baseline, $42.3 \%(95 \%$ CI $41.7-43.4)$ of the patients had changes of their previous clinical condition (from osteoporosis to osteopenia or normal T-score value, or from osteopenia to normal T-score value). Furthermore, the percentage of patients with a decrease of their BMD was higher than those patients who did not have changes of their BMD. Our findings may be different to other clinical studies for the following reasons: the type of clinical study (cross-sectional study, cohort study, retrospective cohort study), study population, type of bone structure analysed (lumbar spine, femoral neck, trochanter, proximal femur, total hip, hip trochanter and diaphysis of the radius), dose ( $5 \mathrm{mg}, 35 \mathrm{mg}, 75 \mathrm{mg}$ or $150 \mathrm{mg}$ ), administration (daily, once-weekly, 2 consecutive days each month or 1 a month), duration of treatment (12 months, 2, 3 and 5 years) and the presentation of our study drug in combination with vitamin D3, in a single pill. Another important difference between our study population and other populations is that $68.6 \%$ were aged $\geq 60$ years. We find that the probability of an increase in BMD is similar in patients with osteopenia and osteoporosis during a period of 18 months of drug administration; however, 6 months after this period the probability changes. For 2 years of treatment the probability of an increase of BDM is approximately $90 \%$ and $95 \%$ for patients with osteoporosis and osteopenia, respectively.

\subsection{Limits and Recommendations}

The present study had the limitation than we did not include a comparative interventional group such as a placebocontrolled group or a group treated with mono-therapy administration of risedronate every 24 hours or once-weekly. In addition, we described only the changes in BMD before and after treatment using a bone densitometer. Therefore, we could not ascertain the direct relationship between drug efficacy and fracture reduction. However, there are several studies that have reported only the increase of BMD in several parts of the body. Other studies have reported the reduction of bone turnover and the risk of vertebral and non-vertebral bone fractures using mono-therapy administration of Risedronate $(5 \mathrm{mg})$ every 24 hours or once-weekly $[4-6,26,27]$. Despite these disadvantages, our results allow us to generate several recommendations. All patients with osteopenia and osteoporosis could receive 18 months of treatment with risedronate and vitamin D3 with a low probability of reduction of their BMD. After this period of time, the patients with osteoporosis could decrease their BMD. However, the performance of the suggested practical approach must be rigorously assessed and the clinician's judgement remains paramount when making decisions. If a clinician makes the decision to continue with treatment, our findings suggest a strict monitoring of BMD. Furthermore, our results suggest that the risk of unwanted effect in patients with osteoporosis is lower in subjects with age of 60 years or above compared with adults aged $\leq 59$ years, but this result depends of multiples factors. In patients with osteopenia and an age of $\geq 60$ years, we observed that the period of treatment could be extended for another six months with a strict monitoring of their BMD. The probability of an increase in the BMD in this population is 
nearly $80 \%$ during a period of treatment of 30 months. Moreover, a small percentage of patients $(5.4 \%(n=795 ; 95 \%$ CI 4.9-5.9) present with a reduction of their BMD or do not have a change in the $\mathrm{T}$-score value after treatment compared to the baseline T-score. These results can be explained, at least in part, by the genetic background of our population. Several studies have identified polymorphisms in some candidate genes that have been associated with bone mass, osteoporotic fracture or osteoporosis; these include the Vitamin D receptor, the oestrogen receptor, the collagen type I alpha-1 gene [28, 29], interleukin-16 (IL-16; rs11556218) [30], IL-6 (-174 G/C) [31], tumour necrosis factor alpha (TNF- $\alpha ;-308 \mathrm{G}>\mathrm{A})$ [32], IL-10 (-1082G>A) [32], and the osteoprotegerin gene (OPG: g.26395T $>C$ and g.27649A $>\mathrm{G}$ genetic polymorphisms) [33]. However, epigenetic mechanisms are another factor that could explain our results in this particular group of patients. Zhang et al reported that epigenetic mechanisms (DNA methylation and histone modifications) may be associated with osteoporosis in a glucocorticoid-induced osteoporosis mouse model [34]. Additionally, several genes and transcription factors involved in bone formation and bone resorption regulate several cellular and molecular mechanisms that could explain the response of these patients to our study drug. This is because these mechanisms play an important role in regulating biological processes and gene expression [22]. Another important factor is the presence of co-morbidities and the pharmacological interaction between prescribed drugs for these co-morbidities. These drugs could be associated with genetic and epigenetic changes that stimulate several pharmacological responses. It has been established that hyperglycaemia is an important factor that has direct and indirect deleterious effects on osteoblast function and bone formation $[35,36]$, and studies in animal models suggest that insulin resistance might be associated with osteoporosis [37, 38]. Therefore, we recommend the study of the pharmacogenetic and pharmacoepigenetic effects [39] of prescribed drugs, in further studies.

\section{Conclusion}

Our findings support evidence that indicates the duration of treatment with risedronate with vitamin D3 once-weekly depends on the target population. We suggest a strict monitoring of BMD particularly for those patients who have a treatment for more of 18 months due to the risk of decrease BMD. However, the clinician's judgement remains paramount when making decisions about the extension of the period of treatment.

\section{Acknowledgements}

The English Language Editing of this study was funded for Centro de Investigación y Educación Continua, CENINVEC.

\section{Conflict of Interest}

The author reports no conflicts of interest in this work.

\section{References}

[1] International Osteoporosis Foundation. Osteoporosis Facts and Statistics. IOF Data \& Publications Website, Available: https://www.iofbonehealth.org/facts-statistics\#category-14 Accessed 24 October 2016.

[2] World Health Organization. WHO Scientific group of the assessment of osteoporosis at primary health care level. Summary Meeting Report Brussels, Belgium, 5-7 May 2004; Geneva, 2007.

[3] Padilla-Vázquez AV, Lamadrid-Figueroa H, Cruz-Valdez A. [Weight, fat percentage and maternal bone mineral density are determinants of bone mineral density in adolescent and young adult females]. Bol Med Hosp Infant Mex. 2007; 64: 72-82. [Article in Spanish].

[4] Mortensen L, Charles P, Bekker PJ, et al. Risedronate increases bone mass in an early postmenopausal population: two years of treatment plus one year of follow-up. J Clin Endocrinol Metab. 1998; 83 (2): 396-402.

[5] Fogelman I, Ribot C, Smith R, et al. Risedronate reverses bone loss in postmenopausal women with low bone mass: results from a multinational, double-blind, placebo-controlled trial. BMD-MN Study Group. J Clin Endocrinol Metab. 2000 May; 85 (5): 1895-900.

[6] Harris ST, Watts NB, Genant HK, et al. Effects of risedronate treatment on vertebral and nonvertebral fractures in women with postmenopausal osteoporosis: a randomized controlled trial. JAMA. 1999; 282 (14): 1344-52.

[7] Reginster JY, Minne HW, Sorensen OH, et al. Randomized trial the effects of risedronate on vertebral fractures in women with established postmenopausal osteoporosis. Osteoporos Int. 2000; 11: 83-91.

[8] Brown JP, Kendler DL, McClung MR, et al. The efficacy and tolerability of risedronate once a week for the treatment of postmenopausal osteoporosis. Calcif Tissue Int. 2002; 71 (2): 103-11.

[9] Rosen CJ, Hochberg MC, Bonnick SL, et al. Treatment with once-weekly alendronate $70 \mathrm{mg}$ compared with once-weekly risedronate $35 \mathrm{mg}$ in women with postmenopausal osteoporosis: a randomized double-blind study. J Bone Miner Res. 2005; 20 (1): 141-51.

[10] Boonen S, Orwoll ES, Wenderoth D, et al. Once-weekly risedronate in men with osteoporosis: results of a 2-year, placebo-controlled, double-blind, multicenter study. J Bone Miner Res. 2009; 24 (4): 719-25.

[11] Chung HY, Chin SO, Kang MI, et al. Efficacy of risedronate with cholecalciferol on 25-hydroxyvitamin D level and bone turnover in Korean patients with osteoporosis. Clin Endocrinol (Oxf). 2011; 74 (6): 699-704.

[12] Reid DM, Hughes RA, Laan RF, et al. Efficacy and safety of daily risedronate in the treatment of corticosteroid-induced osteoporosis in men and women: a randomized trial. European Corticosteroid-Induced Osteoporosis Treatment Study. J Bone Miner Res. 2000; 15 (6): 1006-13.

[13] McClung MR, Miller PD, Brown JP, et al. Efficacy and safety of a novel delayed-release risedronate $35 \mathrm{mg}$ once-a-week tablet. Osteoporos Int. 2012; 23 (1): 267-76. 
[14] Kishimoto H. Efficacy and tolerability of risedronate for the treatment of osteoporosis. Clin Calcium. 2008; 18 (10): 1417 26.

[15] Eastell R, Barton I, Hannon RA, et al. Relationship of early changes in bone resorption to the reduction in fracture risk with risedronate. J Bone Miner Res. 2003; 18 (6): 1051-6.

[16] Seibel MJ, Naganathan V, Barton I, et al. Relationship between pretreatment bone resorption and vertebral fracture incidence in postmenopausal osteoporotic women treated with risedronate. J Bone Miner Res. 2004; 19 (2): 323-9.

[17] Watts NB, Geusens P, Barton IP, et al. Relationship between changes in $\mathrm{BMD}$ and nonvertebral fracture incidence associated with risedronate: reduction in risk of nonvertebral fracture is not related to change in BMD. J Bone Miner Res. 2005 Dec; 20 (12): 2097-104.

[18] Zoehrer R, Roschger P, Paschalis EP, et al. Effects of 3- and 5 -year treatment with risedronate on bone mineralization density distribution in triple biopsies of the iliac crest in postmenopausal women. J Bone Miner Res. 2006; 21 (7): 1106-12.

[19] Cosman F, de Beur SJ, LeBoff MS, Lewiecki EM, Tanner B, Randall S, Lindsay R. Clinician's Guide to Prevention and Treatment of Osteoporosis. Osteoporos Int. 2014; 25 (10): 2359-2381. Published online 2014 Aug 15. doi: 10.1007/s00198-014-2794-2.

[20] Kanis JA, McCloskey EV, Johansson H, Cooper C, Rizzoli R, Reginster J-Y, et al. European guidance for the diagnosis and management of osteoporosis in postmenopausal women. Osteoporos Int. 2013; 24 (1): 23-57. Published online 2012 Oct 19. doi: 10.1007/s00198-012-2074-y.

[21] Robert AA, Fuleihan GE-H, Bauer DC, Camacho PM, Clarke BL, Clines GA, et al. Managing Osteoporosis Patients after Long-Term Bisphosphonate Treatment: Report of a Task Force of the American Society for Bone and Mineral Research. J Bone Miner Res. 2016; 31 (1): 16-35. doi: $10.1002 / \mathrm{jbmr} .2708$

[22] Luis Beltrán-Lagunes, Silvia Munguía-Lozano, Daniel LópezHernández. The effect on bone mineral density in patients with osteoporosis and obesity of once-weekly treatment with Risedronate/vitamin D3 combined in a single pill for 12 months: A post-marketing study. Austin Journal of Endocrinology \& Diabetes. 2014; 1 (4): 8.

[23] Delmas PD, Benhamou CL, Man Z, Tlustochowicz W, Matzkin E, Eusebio R, et al. Monthly dosing of $75 \mathrm{mg}$ risedronate on 2 consecutive days a month: efficacy and safety results. Osteoporos Int. 2008 Jul; 19 (7): 1039-45.

[24] Delmas PD, McClung MR, Zanchetta JR, Racewicz A, Roux C, Benhamou CL, et al. Efficacy and safety of risedronate 150 mg once a month in the treatment of postmenopausal osteoporosis. Bone. 2008 Jan; 42 (1): 36-42.

[25] McClung MR, Zanchetta JR, Racewicz A, Roux C, Benhamou CL, Man Z, et al. Efficacy and safety of risedronate 150-mg once a month in the treatment of postmenopausal osteoporosis: 2-year data. Osteoporos Int. 2013; 24 (1): 293-9.

[26] Reginster J, Minne HW, Sorensen OH, Hooper M, Roux C, Brandi ML, et al. Randomized trial of the effects of risedronate on vertebral fractures in women with established postmenopausal osteoporosis. Vertebral Efficacy with Risedronate Therapy (VERT) Study Group. Osteoporos Int. 2000; 11: 83-91.

[27] Ellis AG, Reginster JY, Luo X, Cappelleri JC, Chines A, Sutradhar S, et al. Bazedoxifene versus Oral Bisphosphonates for the Prevention of Nonvertebral Fractures in Postmenopausal Women with Osteoporosis at Higher Risk of Fracture: A Network Meta-Analysis. Value Health. 2014; 17: 424-432.

[28] Obermayer-Pietsch B, Chararas C, Kotschan S, Walter D, Leb G. Genetic background of osteoporosis. Acta Med Austriaca. 2000; 27 (1): 18-22.

[29] Stewart TL, Ralston SH. Role of genetic factors in the pathogenesis of osteoporosis. J. Endocrinol. 2000; 166 (2): 235-45.

[30] Ma X, Chen Y, Zhang Q, Tian H, Wang J, Liu S, et al. Interleukin-16 rs11556218 is associated with a risk of osteoporosis in Chinese postmenopausal women. Eur J Obstet Gynecol Reprod Biol. 2016; 210: 90-93.

[31] Fajar JK, Azharuddin A. The association between interleukin 6-174 G/C gene polymorphism and the risk of osteoporosis: A meta-analysis. Journal of Taibah University Medical Sciences, In press, corrected proof, Available online 6 October 2016.

[32] Kotrych D, Dziedziejko V, Safranow K, Sroczynski T, Staniszewska M, Juzyszyn Z, et al. TNF- $\alpha$ and IL10 gene polymorphisms in women with postmenopausal osteoporosis. Eur J Obstet Gynecol Reprod Biol. 2016; 199: 92-5.

[33] Sun T, Chen M, Lin X, Yu R, Zhao Y, Wang J. The influence of osteoprotegerin genetic polymorphisms on bone mineral density and osteoporosis in Chinese postmenopausal women. Int Immunopharmacol. 2014; 22 (1): 200-3.

[34] Zhang Y, Ma C, Liu X, Wu Z, Yan P, Ma N, et al. Epigenetic landscape in PPAR $\gamma 2$ in the enhancement of adipogenesis of mouse osteoporotic bone marrow stromal cell. Biochim Biophys Acta. 2015; 1852 (11): 2504-16.

[35] Tamura Y, Kawao N, Yano M, Okada K, Matsuo O, Kaji H, et al. Plasminogen activator inhibitor-1 deficiency ameliorates insulin resistance and hyperlipidemia but not bone loss in obese female mice. Endocrinology. 2014; 155: 1708-1717.

[36] Mazziotti G, Bilezikian J, Canalis E, Cocchi D, Giustina A. New understanding and treatments for osteoporosis. Endocrine. 2012; 41: 58-69.

[37] Ogata N, Chikazu D, Kubota N, Terauchi Y, Tobe K, Azuma $\mathrm{Y}$, et al. Insulin receptor substrate-1 in osteoblast is indispensable for maintaining bone turnover. J Clin Invest. 2000; 105: 935-943.

[38] Cao JJ, Sun L, Gao H. Diet-induced obesity alters bone remodeling leading to decreased femoral trabecular bone mass in mice. Ann N Y Acad Sci. 2010; 1192: 292-297.

[39] López-Hernández D. Polymorphisms of cytochrome P450 are potential candidates that could potentially help clinicians on the treatment of cardiovascular diseases among Asian populations. Indian Heart J (2017), http://dx.doi.org/10.1016/j.ihj.2017.02.016. 